\title{
The concept of the taxon cycle in biogeography
}

\author{
ROBERT E. RICKLEFS * and ELDREDGE BERMINGHAM† \\ *Department of Biology, University of Missouri-St Louis, 8001 Natural Bridge Road, St Louis, MO 63121-4499, U.S.A.; †Smithsonian Tropical \\ Research Institute, PO Box 2072, Balboa, Republic of Panama/Unit 0948, APO AA 34002-0948, U.S.A.
}

\begin{abstract}
Taxon cycles are sequential phases of expansion and contraction of the ranges of species, associated generally with shifts in ecological distribution. The important contribution of the taxon cycle to biogeographical analysis is its emphasis on evolutionary and ecological interactions among colonizing and resident species, which influence their extinction dynamics and establish patterns of geographical distribution. Taxon cycles were inferred originally from the distribution of species across island archipelagos, where a correlation was noted between gaps in island occupancy and the degree of phenotypic differentiation. This pattern implied that phases of colonization were followed by range contraction, while endemic Antillean species that were undifferentiated between islands suggested secondary expansion and the beginning of a new cycle. This interpretation was met with scepticism, but reconstruction of phylogenetic relationships from gene sequences has now permitted us to characterize taxon cycles in Lesser Antillean birds. The relative timing of phases of the
\end{abstract}

cycle can be deduced from genetic divergence between island populations. We have found that taxon cycles have periods in the order of $10^{6}$ years and that cycles in different lineages occur independently of each other and independently of Pleistocene climate cycles. Individual island populations may persist for several millions of years on the larger islands of the Lesser Antilles; occasional expansion phases lead to the replacement of island populations that have disappeared, thus reducing the archipelago-wide rate of extinction to nil. What drives taxon cycles is unknown, but we speculate that they may be caused by co-evolution with enemy populations, and a probable mechanism would involve infrequent mutations influencing parasite virulence and avian host disease resistance. Taxon cycles undoubtedly occur on continents, but the geographical configuration of island archipelagos reveals more clearly their presence and invites their study.

Key words co-evolution, colonization, extinction, habitat distribution, island biogeography, Lesser Antilles, phylogeography, taxon cycles.
Taxon cycles are sequential phases of expansion and contraction of the ranges of species, associated usually with shifts in ecological distribution and adaptations to changing ecological relationships through the cycle (Wilson, 1959, 1961). So defined, taxon cycles have relevance to a variety of issues in biogeography including responses to global climate change, vulnerability to extinction, and the origin and control of invasive species (Whittaker, 1998). However, in spite of its central position, the concept of the taxon cycle is vague in the minds of many biogeographers and has been rejected outright by others. We have recently used molecular phylogenetic methods to characterize the history of colonization and extinction in Lesser Antillean birds (Ricklefs \& Bermingham, 1999). Consequently, this is an opportune time to re-evaluate the taxon cycle concept and the empirical data that have been

Correspondence: Robert E. Ricklefs, Department of Biology, University of Missouri-St Louis, 8001 Natural Bridge Road, St Louis, MO 63121-4499, U.S.A. E-mail: ricklefs@umsl.edu used to support it. We provide a brief history of the concept and then review how molecular phylogenetic data demonstrate the existence of taxon cycles in the avifauna of the Lesser Antilles. Finally, we address the fundamental issue of the factors that drive taxon cycles.

The idea that taxa pass through phases of expansion and contraction, whether in diversity, geographical distribution or ecological relationship, has been a persistent theme in evolutionary biology and biogeography (Willis, 1922; Brown, 1957; Darlington, 1957; Carson, 1959). Some authors have compared these phases to life-cycle stages of youth, maturity and senescence of the individual, but such analogies provide little insight into the different processes involved at each level of organization (Cain, 1944; Simpson, 1949; Ricklefs \& Bermingham, 1999).

Wilson $(1959,1961)$ coined the term 'taxon cycle' for island populations and distinguished expanding and contracting phases by patterns of geographical distribution. $\mathrm{He}$ further described the relationship between ecological and 
geographical distribution for ants on islands in Melanesia. Expanding and widespread taxa often had identifiable continental sources and occupied marginal, lowland habitats at the edges of islands. Contracting taxa exhibited reduced or fragmented ranges and typically occupied interior and montane, forested habitats. Wilson's work implied clearly that shifts between expanding and contracting taxon cycle phases were accompanied by complementary habitat shifts. Wilson suggested that habitat shifts by older taxa were driven by competition from newly arriving colonists in marginal habitats, but he raised the possibility that late-stage species could undertake new phases of expansion through marginal habitats.

Greenslade (1968b, 1968a, 1969) and Ricklefs (1970) confirmed the relationship between late-stage species, identified by gaps in their geographical range, and restricted habitat distribution for birds and insects in several island groups (also see Cox \& Ricklefs, 1977; Ricklefs \& Cox, 1978; Williamson, 1981; Spitzer et al., 1993). To provide a connection between taxon cycle stages and time, Ricklefs \& Cox (1972) followed the lead of Greenslade (1968b) and used geographical distribution and taxonomic diversification to infer a temporal sequence. Early-stage Lesser Antillean birds were undifferentiated phenotypically and distributed continuously across island archipelagos, or relatively so, whereas late-stage species were characterized by gaps in their distribution and increasing phenotypic differentiation. Eventually these became endemic species on a single island before disappearing completely. Ricklefs \& Cox also suggested that the competitive ability of a taxon varied through the cycle owing to changes in co-evolutionary relationships with enemies, providing a mechanism internal to the biological community to drive the cycle. Because evolutionary success in a victimenemy relationship may be frequency dependent (Pimentel, 1961; Pimentel \& Al-Hafidh, 1963; Pimentel et al., 1965), Ricklefs \& Cox (1972) suggested that populations of late-stage species could initiate new phases of expansion if they escaped the attention of predators or parasites after becoming rare. Under such circumstances, genetic change might free a host from its predator or parasite and drive new expansion phases. Finally, Ricklefs \& Cox suggested that taxon cycles occurred probably in continental biotas but were difficult to recognize in the absence of the discrete and telltale patterns of distribution found within groups of islands.

Since Wilson (1961) and Ricklefs \& Cox (1972), several modifications of the taxon-cycle concept have been published, most notably Erwin's (1981) taxon pulse and Roughgarden \& Pacala's (1989) proposal of a taxon cycle in Lesser Antillean Anolis populations. Erwin defined a taxon pulse as 'a taxon's adaptive shift from one habitat to another' along deterministic pathways, depending on the taxon. Based on his study of carabid beetles, Erwin argued that taxon pulses always flow to suboptimal habitats and distant regions: from the ground surface litter of wet tropical forests to forest canopies, high latitude, high elevation and arid habitats. Pulses are driven by a variety of ecological factors, including habitat change and competition, that select for habitat shifts. An important aspect of Erwin's idea is that each taxon has a core set of favourable habitats within which most of the stem lineages diversify. Taxon pulses are irreversible, and habitat shifts reflect progressive specialization to conditions that are extreme for the taxon.

Each island in the Lesser Antilles has either one or two species of Anolis lizard. To explain this pattern, Roughgarden \& Pacala (1989) proposed a scenario of sequential colonization of an island by a second larger species of lizard, which forces the first to become smaller and, finally, to go extinct. In the process, the larger newcomer evolves a smaller body size, thereby making itself vulnerable to subsequent competitive exclusion by a new larger colonist. These cycles are driven by colonization and by asymmetric competition that favours the larger newcomer. Taper \& Case (1992) explored several evolutionary models of competition and character displacement that demonstrated the feasibility of the Roughgarden \& Pacala (1989) concept of the taxon cycle, but also showed that the relative size of the invader and the direction of size change depends on the model used. However, Matsuda \& Abrams (1994) also showed theoretically that a species might drive itself to extinction under extreme intraspecific competition, in contrast to the asymmetric interspecific competition that drives character divergence and extinction under the RoughgardenPacala model. Thus, modelling produces a broad range of possible outcomes of competition following colonization and some, but not all, of these are consistent with a taxon cycle scenario of competitive displacement of established residents by newcomers.

Regardless of its particular incarnation, the concept of the taxon cycle has had a varied and not altogether enthusiastic reception. Pielou (1979) suggested that taxon cycle stages reflected the effects of short-term variation in climate and impacts of unusual weather. She said that '... the whole taxon cycle may simply be the effect of sporadically occurring climatic "bad years" on species-populations too isolated for losses to be quickly made good from nearby populations. It is noteworthy that the cycle has been observed in birds and insects, flying and wind-dispersed animals that can be forced into stage I of the cycle by an exceptional storm.'

In a more detailed and specific response to Ricklefs and Cox's application of the taxon-cycle concept to birds of the West Indies, Pregill \& Olson, (1981) raised seven objections. (i) The concept is a tautology in the sense that any conceivable distribution of a lineage over a set of islands could be placed in one or another stage of the taxon cycle. (ii) Taxon cycle stages did not represent a temporal sequence. (iii) Different evolutionary histories of lineages can yield similar stages. (iv) Not all lineages progress through the taxon cycle. (v) Stage IV 
(single-island endemic species) can be generated by evolutionary differentiation between island populations leading to taxonomic distinction as different species. (vi) Some singleisland endemic species are not relict populations, hence not the final stages of formerly widespread species. (vii) Counteradaptation (co-evolution between birds and their enemies) is not a logical mechanism for driving the taxon cycle. On this last point, they stated that 'Ecological doctrine and good sense revolt at the idea that a species with a long history of adaptation to a particular environment would be at a competitive disadvantage with newly arriving colonists.' Pregill \& Olson (1981: 91) went on to say 'The concept of "counteradaptation" is an artificial construct needed to explain a nonexistent phenomenon - the taxon cycle. The patterns of distribution that constitute the "stages" of the taxon cycle are more reasonably interpreted in terms of the effects that the cycling of habitats had on species during the alternate wet and dry periods of the Pleistocene, in combination with the varying dispersal abilities of individual species.' Clearly, the main issue was the reality of taxon cycles themselves.

Pregill \& Olson (1981) also raised the troubling concern that extinction of species caused by human activity may have obliterated natural patterns of distribution and made historical and ecological analyses of island faunas problematic at best (see also Steadman, 1995). Vertebrate faunas of many oceanic islands have suffered extensive extinction (Steadman, 1989; James \& Olson, 1991). Fossil remains show that a large proportion of the avifauna of many West Indian islands disappeared as a consequence of the loss of arid habitats following the last glacial maximum and the arrival of humans in the islands some 4000 years ago (Pregill et al., 1994). However, most cases of extinction of birds from islands in the Lesser Antilles were of aquatic species, raptors and parrots, and most small land birds remain. Forty-three island populations of doves, hummingbirds and songbirds have been reported from fossil deposits on St Eustatius, Antigua, Barbuda and Montserrat, which are small islands in the northern Lesser Antilles (Pregill et al., 1994). Of these, only six are missing from the contemporary avifaunas of the islands (Raffaele et al., 1998). Similar data are unavailable for the larger core islands of the Lesser Antilles, which probably suffered fewer extinctions. Although human-caused extinction is a problem for the study of biogeography, it appears not to be overwhelming among small land birds of the Lesser Antilles.

Because the taxon cycle is an historical model, tests of the existence of taxon cycles require historical assessment. In the absence of a fossil record, biogeographers must rely on phylogenetic methods to reconstruct the past history of lineages. One of the first attempts to do this explicitly was that of Liebherr \& Hajek (1990), who examined habitat shifts superimposed upon cladistic hypotheses of relationships among eight clades of Caribbean and Central American carabid beetles. They failed to find strong evidence of the type of habitat shifts predicted by Erwin's taxon-pulse hypothesis. They also rejected the taxon cycle model for this reason, but presumed mistakenly that a derived phylogenetic position reflected a late stage of the taxon cycle, which it does not (Cox, 1990). Nor does the taxon cycle model propose irreversible habitat change, as in the case of the taxon pulse. Thus, Liebherr \& Hajek's (1990) test is inconclusive with respect to the taxon cycle.

Losos (1990) used phylogenetic hypotheses based on a variety of biochemical, karyotypic and morphological characters to test the taxon cycle model of Roughgarden \& Pacala (1989) for Lesser Antillean anoles. The evolutionary transition from large to small anoles hypothesized by Roughgarden $\&$ Pacala should result, in some instances, in a sister relationship between a size-shifted small species and its large-bodied ancestral stock on another island. Contrary to predictions, Losos found little evidence for size shifts in Anolis and species belonging to a particular size class on different islands were generally closely related (see also Miles \& Dunham, 1996; Schneider et al., 2001).

During the past decade, Eldredge Bermingham's laboratory at the Smithsonian Tropical Research Institute has been undertaking molecular phylogenetic analyses of the birds of the West Indies based on mitochondrial DNA (mtDNA) sequences (Seutin et al., 1993; Seutin et al., 1994; Bermingham et al., 1996; Lovette et al., 1998; Lovette et al., 1999a, 1999b; Ricklefs \& Bermingham, 1999; Hunt et al., 2001). Overlaying phylogeny on geography has allowed us to identify the relative time of colonization of West Indian lineages, based on genetic divergence between island populations and their mainland sister populations or sister species, and to characterize secondary expansions of taxa within the West Indies (Figs 1 and 2). Preliminary analyses of the phylogenetic data for birds of the Lesser Antilles were reported by Ricklefs \& Bermingham (1999). The results showed: (a) that the taxon cycle stages designated by Ricklefs \& Cox (1972) represent a temporal sequence; (b) that the maximum age of taxa in the Lesser Antilles may be 7.5-10 million years (My, based on a rate calibration of $1.5-2 \% \mathrm{mtDNA}$ sequence divergence per million years) and individual island populations may be as old as $4 \mathrm{My}$; (c) that many taxa have undergone phases, and in some cases multiple phases, of secondary expansion within the Lesser Antilles; and (d) that phases of expansion and contraction are not correlated between taxa or with glacial climate transitions. In a few cases, multiple colonization or secondary expansion has resulted in the co-existence of moderately differentiated lineages within individual island populations (Klein \& Brown, 1994; Hunt et al., 2001). Finally, the absence of gaps in the island distributions of early-stage species supports a stepping-stone model of colonization and secondary expansion. 


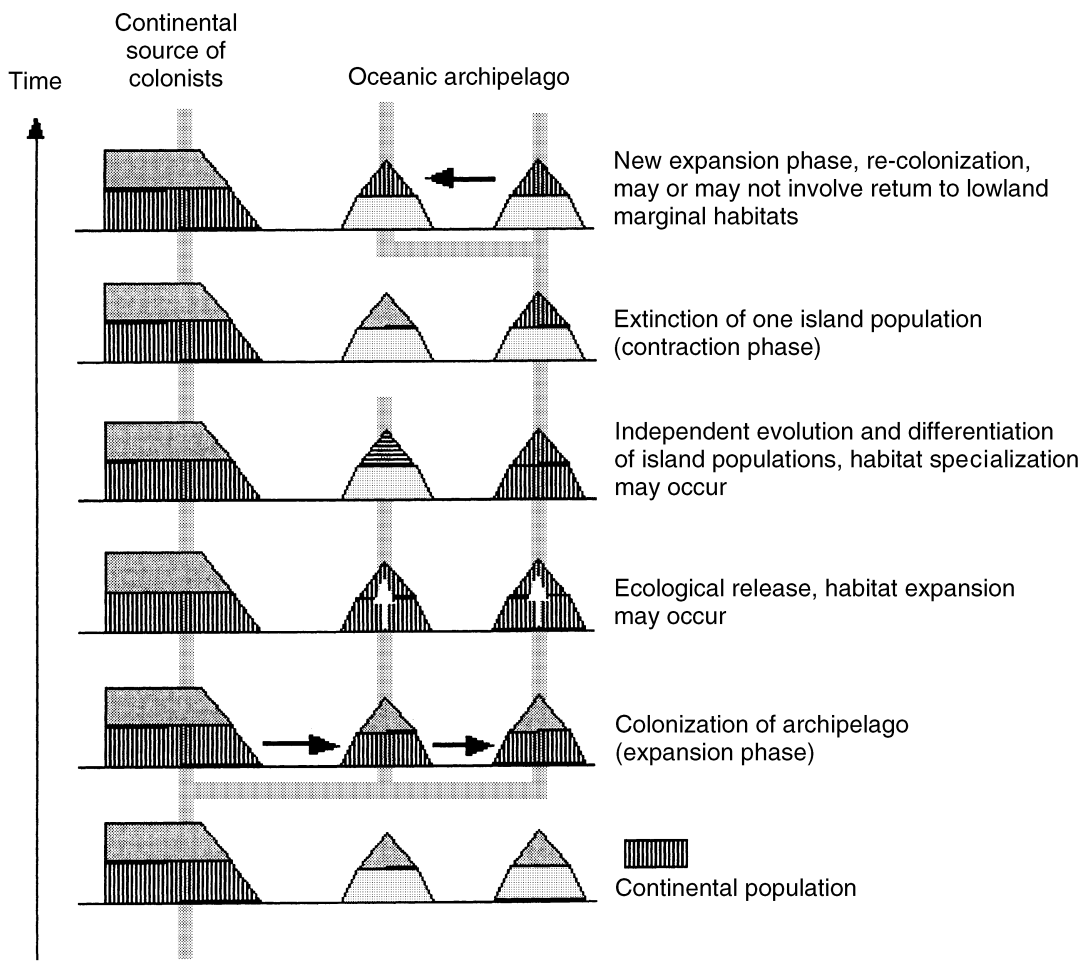

Fig. I A schematic diagram of changes during expansion and contraction phases of the taxon cycle including secondary expansion of a taxon's distribution within the island archipelago. The thick grey line represents the underlying phylogenetic relationships between the island populations. Time runs from the bottom to the top of the diagram. Only present-day populations are sampled, but the extinction of the population in the near island can be inferred when one assumes that colonization takes place in stepping-stone fashion.

Molecular phylogenetic analyses show that objections i, ii, iii, v and vi of Pregill \& Olson (1981) are not concerns after all. Birds clearly go through phases of range expansion and subsequent extinction of island populations (contraction) that correspond to the Ricklefs \& Cox (1972) stages of the taxon cycle (points i, ii, and iii). Stage IV species (single-island endemic populations that are not part of species complexes) have sister relationships to continental rather than Lesser Antillean populations (point v), and all such species are among the oldest in the archipelago (point vi). Phylogenetic analysis cannot address point (iv), that some species do not progress through the cycle, because it cannot distinguish recent colonization (stage I) from ongoing gene flow, lack of differentiation and continued rescue (Brown \& Kodric-Brown, 1977) of island populations, which would prevent movement through the taxon cycle. However, the involvement of all species in all settings is not a necessary condition of the taxon cycle model. Point (vii), regarding counteradaptation as a mechanism to drive the cycle, will be discussed further below, but also is not a necessary condition for verifying the existence of the cycle itself.

Ricklefs \& Bermingham (1999) also showed that populations in later stages of the taxon cycle have narrower habitat distributions skewed towards forested and montane habitats, and a tendency towards lower population density in the habitats in which they occur. Thus, as indicated in previous studies (Wilson, 1961; Greenslade, 1968b; Ricklefs \& Cox, 1972), geographical distribution (colonization and extinction) and local ecological distribution are correlated, evidently because they express the same set of underlying processes. Island populations of a given species become evolutionarily independent early in the taxon cycle, judging by the appearance of fixed genetic differences between them. None the less, the independent island populations of a particular species appear to progress through the taxon cycle at similar rates. This can be seen in the general correlation within species in habitat distribution on different islands. In particular, late-stage species in which one or more island populations have gone extinct, leaving a gap in the geographical distribution, typically show restricted habitat distribution and low abundance on all the islands on which they persist. Thus, progression through taxon cycle is, to some degree, predictable, or deterministic — one might even say inevitable.

Assuming that nucleotide substitution proceeds at a uniform rate, various avian, particularly passerine, molecular clock calibrations relate mtDNA genetic divergence to time at 


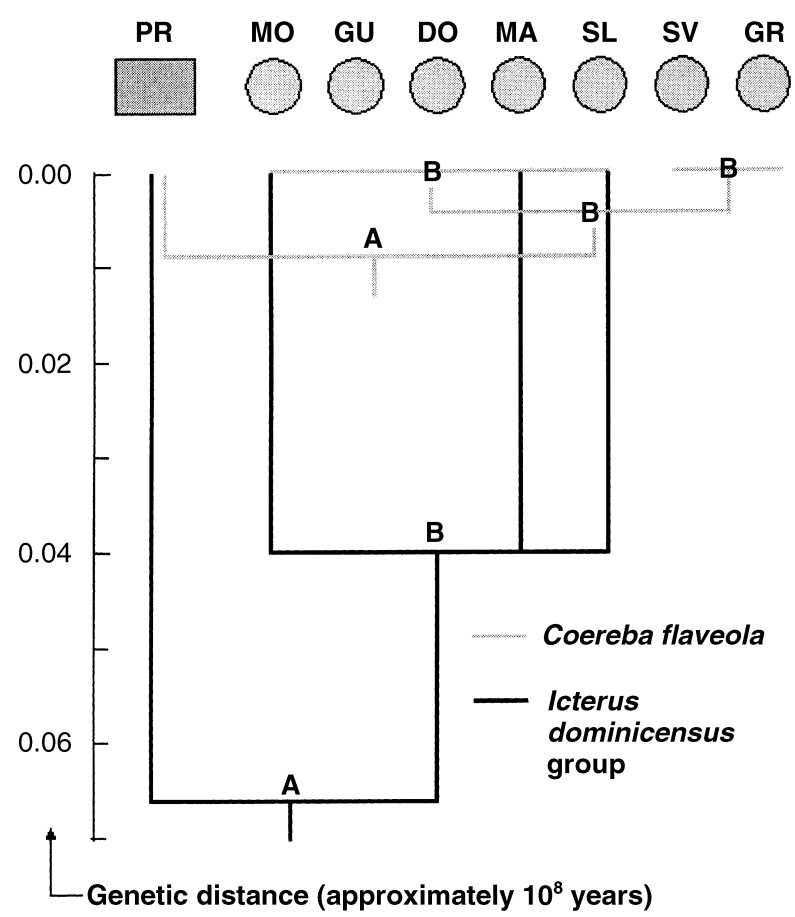

Fig. 2 Phylogenetic hypotheses for the relationships among island populations of the bananaquit (Coereba flaveola) and the Icterus dominicensis group of endemic orioles (see Seutin et al., 1994; Lovette et al., 1999a) demonstrating two different temporal and spatial patterns of colonization, expansion and differentiation. The scale refers to branch lengths in terms of the proportion of mtDNA nucleotide substitutions, corrected for multiple substitutions (Tamura-Nei distances), which occur at about $10^{-8}$ per year. Branch points A refer to the initial colonization of the Lesser Antilles, from the Greater Antilles in these species. Branch points B represent secondary expansion phases within the Lesser Antilles. Locations are: PR, Puerto Rico; MO, Montserrat; GU, Guadeloupe; DO, Dominica; MA, Martinique; SL, St Lucia; SV, St Vincent; GR, Grenada.

1.5-2\% per million years (Klicka \& Zink, 1997; Fleischer et al., 1998). Although estimates of time are imprecise owing to the uncertainty of this calibration and the stochastic nature of nucleotide substitution, genetic divergence does allow one to approximate the ages of island populations. The earliest colonization event among species that we have surveyed in the Lesser Antilles is the Lesser Antillean tanager Tangara cucullata, whose closest continental relative is probably the South American T. cayana at a distance of $17.7 \%$, or a divergence time of 9-12 My. Twenty lineages have colonization times distributed relatively uniformly between 1.5 and $15 \%$ sequence divergence, or $0.75-10 \mathrm{My}$. An additional 17 lineages colonized the Lesser Antilles more recently than 0.55-0.75 My; that is, at about the onset of pronounced glacial cycles. We believe that this shift in the accumulation rate of colonists reflects either a dramatic change in the rate of colonization associated with the onset of major Pleistocene climate oscillations and concomitant habitat changes or a mass extinction event of unknown cause in the avifauna of the archipelago (Ricklefs \& Bermingham, 2001).

Endemic Lesser Antillean species restricted to one island (Catheropeza bishopi, Melanospiza richardsoni), or two adjacent islands (Cyanophaia bicolor, Myiarchus nugator, Dendroica plumbea) colonized the archipelago 4-6.5 My ago. The oldest divergences between sister populations on different Lesser Antillean islands date to about 1.5-2.1 My (Dendroica adelaidae) (Lovette et al., 1998), 3.4-4.5 My (Cichlherminia lherminieri) (unpublished data) and 4.1-5.4 My (Icterus dominicensis superspecies group) (Lovette et al., 1999a). The oldest example of secondary expansion within the Lesser Antilles dates to approximately 6.5-8.6 My, and phylogenetic trees reveal nine additional instances of secondary expansion before the middle of the Pleistocene.

These age estimates suggest that taxon cycles in the Lesser Antillean avifauna are independent of the glacial climate cycles of the latter part of the Pleistocene, although fluctuations in climate also occurred before then. Certainly many island populations of Lesser Antillean birds have survived multiple cycles of climate change during the past million years, but we cannot know the number of taxa that were driven to extinction from the archipelago as a whole during this period. Based on gaps in the distribution of extant species of Lesser Antillean birds, we have estimated the extinction rate of individual island populations to be no more than 0.14 per percentage sequence divergence, on average (Ricklefs \& Bermingham, unpublished data). This is equivalent to an average life span of individual island populations of 3.6-4.8 My. Because secondary expansion of taxa occurs relatively frequently compared to the extinction of individual island populations, missing island populations are re-established and the persistence of the species in the archipelago as a whole is very long. In fact, Ricklefs \& Bermingham (2001) could detect no significant background rate of archipelago-wide extinction in Lesser Antillean birds. As mentioned above, we concluded instead that a heterogeneous history of colonization and perhaps a mass extinction event at about $0.55-0.75 \mathrm{My}$ ago have determined contemporary avian diversity in the archipelago as a whole. We presume that the superposition of this abrupt transition upon ongoing taxon cycles might have obscured evidence of some expansion phases and, in the case of a mass extinction event, created patterns that might resemble contraction phases, although this is difficult to assess. Regardless, both the existence of expansion phases prior to the postulated extinction event and the relationship between population age, habitat restriction, and reduced population density support the conclusion that birds pass through taxon cycles.

Although the occurrence of taxon cycles in Lesser Antillean birds is now well established, the causes of movement 
through the cycle and initiation of new cycles are not clear. Nevertheless we can make some inferences from our current understanding of the dynamics of taxon cycles. Most importantly, it appears that cycles are not caused by extrinsic factors that affect many ecologically similar species at the same time. We base this statement on the fact that the time scale of taxon cycles - on the order of $10^{5}-10^{7}$ years - is much longer than the period of most cyclic climate factors, including the glacial cycles of the Pleistocene. The Milankovic cycles that drove the ice ages have periods of 23000,41000 and 100000 years (Dynesius \& Jannson, 2000). In addition, ecologically similar types of species and taxonomically related species are, at present, in all stages of the cycle (Ricklefs \& Cox, 1978).

Ricklefs \& Cox (1972) suggested that taxon cycles were driven by changes in the balance of co-evolution between birds and their enemies and competitors. Accordingly, new immigrants to an island may enter an expansion phase because they have escaped substantial predation or disease. When a newly established population becomes abundant and widespread, adaptation to utilize this relatively unexploited resource is selected in predators and parasites. Over time, this 'counteradaptation' of the local enemy fauna begins to reduce the productivity of the immigrant population, dispersal between islands ceases and habitat distribution and local abundance decrease. By this point, the colonist has entered the contraction phase of the taxon cycle. Because island populations of a single taxon suffer similar fates, they demonstrate correlated restrictions in habitat use, reductions in population size and extinction-based distribution gaps in spite of their evolutionary independence, thus providing both regional and local signals for taxon cycle stages.

Two observations on taxon cycles address important aspects of their dynamics: first, intervals between expansion phases have characteristic times on the order of $10^{6}$ years; secondly, cycles in evolutionarily independent lineages are not synchronized. Lack of synchrony implies that taxon cycles are related to changes in special population-environment relationships, such as host-parasite interactions. Models of host-parasite co-evolution based on shifts in the frequencies of alleles governing parasite virulence and host resistance show an oscillatory type of behaviour with periods of tens to hundreds of generations (Lenski \& May, 1994; Frank, 1996; Roy \& Kirchner, 2000). These models are consistent with the temporal dynamics of most co-evolving laboratory systems (e.g. Pimentel \& Al-Hafidh, 1963; Pimentel et al., 1965; Ebert, 1998). However, oscillations with such short periodicity are not consistent with the longer temporal dynamics of the taxon cycle. A co-evolutionary model can be reconciled with long time periods when changes in the host-parasite relationship are driven by infrequent mutations of large consequence that change the balance between host and parasite populations. For example, acquisition of resistance alleles by a host population could lead to a short-term release from control by disease and initiate a phase of population expansion and colonization. When pathogens respond to this change rapidly, expansion phases of the taxon cycle would be brief. In this regard, taxa having recently expanded through the Lesser Antilles appear to have done so rapidly judging from the absence of significant genetic variation among island populations.

We do not know the extent to which predators and diseases determine population size in Lesser Antillean birds. Introduced predators and disease organisms have been implicated in the recent decline and extinction of populations in many areas of the world (Van Riper et al., 1986; Atkinson et al., 1995; Stattersfield et al., 1998). However, population decline in response to introductions and changes in the landscape brought about by humans reveal little about the long-term persistence of populations of Lesser Antillean birds. To begin to understand the possible role of co-evolution with disease organisms in the taxon cycle, we are using a molecular phylogenetic approach (Ricklefs \& Fallon, 2002) to examine malarial blood parasites of birds (Plasmodium and Haemoproteus) (Atkinson \& Van Riper, 1991). We do not presume that malaria controls host populations, but rather regard the host-malaria interaction as a model system for examining co-evolution, host-sharing and other aspects of host-parasite relationships. Surveys of the prevalence of blood parasites in the Lesser Antilles demonstrate considerable variation among species of host and among island populations within host species. More importantly, they also reveal significant host $\times$ island interactions in parasite prevalence, suggesting that independent host-parasite co-evolution is a possibility (Apanius et al., 2000). Preliminary phylogenetic analysis of parasite lineages indicates substantial host sharing and distribution of lineages across islands (Fallon, Bermingham $\&$ Ricklefs, unpublished data). These attributes should be present if the introduction of new diseases to island populations and host switching by parasites were to function as sources of novel variation in host-parasite systems. Future analyses will provide a more detailed picture of the development and long-term dynamics of the parasite community within the West Indies overlaid on the phylogeography of their hosts.

Analyses of island systems, particularly in archipelagos, have been crucial in the development of ideas about the dynamics of species ranges (Lack, 1947; MacArthur \& Wilson, 1967; Lack, 1976; Wagner \& Funk, 1995; Blondel, 2000; Grant, 2001). The discrete distribution of populations across linearly arranged, ecologically similar islands, such as the inner arc of the Lesser Antilles, permits one to assess genetic differentiation between island populations as a measure of migration and evolutionary independence. Assuming stepping-stone colonization, one may interpret gaps in ranges as extinction of individual island populations. In addition, continental sister taxa, which are the ultimate source of island 
taxa, serve as reference points for the history and geography of island forms. Taxon cycles undoubtedly occur in continental settings, although stages of the cycle are difficult to identify unambiguously owing to the ecological and geographical complexity of continental regions and the absence of a clear reference to the origin of individual continental taxa. None the less, it is tempting to assign taxon cycle stages to continental taxa based on size of geographical range, taxonomic or genetic differentiation between subpopulations in different parts of the range and disjunctions in distribution (Gaston, 1998).

Before concluding, we ask whether taxon cycles provide insights into such contemporary issues as climate change, vulnerability to extinction, invasive species and emerging diseases. As in most of the world's tropics, the Lesser Antilles endured dramatic changes in climate during the Pleistocene, particularly cooler and drier conditions during glacial maxima. These changes must have caused the distributions of populations within islands to shift with areas of suitable habitat. Climate change apparently did not cause marked extinction of island populations; over-water barriers to dispersal prevented geographical shifts over the Lesser Antilles as a whole. Thus, Lesser Antillean birds have shown a high resistance to changing ecological conditions within islands, but their situation does not address fairly the fate of taxa in larger continental settings. We can say with some certainty that most of the contemporary variation in abundance and habitat distribution among small land birds within the Lesser Antilles islands is unrelated to climate, but rather probably reflects the outcome of co-evolutionary relationships with enemies and competitors. Ricklefs \& Cox (1972) showed that vulnerability of island populations to anthropogenic causes of extinction (for example, habitat destruction, introduced predators) is higher among species in contraction phases of the taxon cycle (stages III and IV contrasted with stages I and II). This relationship holds for birds in the Galápagos and Hawaiian Islands, as well (Cox, 1990; Ricklefs \& Bermingham, 1999). A regional phylogeographical assessment combined with the local ecological distribution and status of populations should allow conservationists to identify populations of concern. In the Lesser Antilles, all island populations listed as endangered or vulnerable (Stattersfield et al., 1998) belong to the class of old endemic taxa that have not experienced recent phases of expansion.

Expansion could be thought of as spontaneous invasiveness, accompanied by increased habitat distribution and colonization of neighbouring islands. When these phases are caused by release from one or more predators or disease organisms, such invasiveness may resemble the behaviour of an introduced population that leaves its natural predators and parasites behind in its native range (Sax \& Brown, 2000). Species in expanding phases of the taxon cycle may provide useful models for investigating general ecological or evolutionary properties of invasive species, particularly because such species remain connected to their natural environments and ecological communities. We have not yet examined the association of host switching or increase in prevalence or virulence of disease organisms with phases of the taxon cycle. If these factors are important, the long-term stability of avian populations in the Lesser Antilles suggests that they do not frequently drive populations to extinction, but may be ameliorated by reduced transmission associated with habitat restriction, habitat shift or reduced population density. For most of their life spans, populations of Lesser Antillean birds are restricted to individual islands within which any adjustments to environmental factors must take place. Evidently, in spite of continuing co-evolutionary pressure and changing environmental conditions, birds are able to adapt well enough ecologically and evolutionarily to persist for very long periods.

How general are taxon cycles among other groups of organisms and in other archipelagos? We recognize the stages of the cycle by characteristic patterns of genetic differentiation and extinction (distribution gaps) of island populations. These manifestations of phases of expansion and contraction only appear when the size and distances between islands match the dispersal capacities and persistence qualities of populations in a certain way. When islands are too close, migration between islands prevents differentiation, rescue prevents extinction and populations do not develop evolutionary independence. When islands are too distant or too small to hold taxa, the biota may be too impoverished to show the variety of patterns needed to recognize different phases of the cycle and unique explanations devoid of generality are required for the history of each taxon. We may have been fortunate to work with birds in the Lesser Antilles; however, similar patterns of distribution and taxonomic or genetic differentiation have been identified in many groups in many different island systems (e.g. Cox, 1990). Thus, we believe that alternating phases of expansion and contraction are nearly universal and that it is possible to study taxon cycles analytically in a wide variety of groups and regions.

\section{ACKNOWLEDGMENTS}

Our work in the West Indies has been supported by the National Geographic Society, Smithsonian Institution and National Science Foundation. We are grateful to many individuals for assistance in the field and laboratory, particularly Drs Gilles Seutin and Irby Lovette. This work would not have been possible without the extraordinary co-operation and support of various agencies of the governments in the West Indies.

\section{REFERENCES}

Apanius, V., Yorinks, N., Bermingham, E. \& Ricklefs, R.E. (2000) Island and taxon effects in the prevalence of blood parasites and 
activity of the immune system in Lesser Antillean birds. Ecology, 81, 1959-1969.

Atkinson, C.T. \& Van Riper, C. III (1991) Pathogenecity and epizootiology of avian hematozoa. Plasmodium, Leucocytozoon and Haemoproteus. Bird-parasite interactions. Ecology, evolution, and behavior (ed. by J.L. Loye and M. Zuk), pp. 20-48. Oxford University Press, New York.

Atkinson, C.T., Woods, K.L., Dusek, R.J., Sileo, L.S. \& Iko, W.M. (1995) Wildlife disease and conservation in Hawaii - pathogenicity of avian malaria (Plasmodium relictum) in experimentally infected Iiwi (Vestiaria coccinea). Parasitology, 111 (Suppl. S), S59-S69.

Bermingham, E., Seutin, G. \& Ricklefs, R.E. (1996) Regional approaches to conservation biology: RFLPs, DNA sequence, and Caribbean birds. Molecular genetic approaches in conservation (ed. by T.B. Smith and R.K. Wayne), pp. 104-124. Oxford University Press, New York.

Blondel, J. (2000) Evolution and ecology of birds on islands: trends and prospects. Life and Environment, 50, 205-220.

Brown, W.L. Jr (1957) Centrifugal speciation. Quarterly Review of Biology, 32, 247-277.

Brown, J.H. \& Kodric-Brown, A. (1977) Turnover rates in insular biogeography: effect of immigration on extinction. Ecology, 58, 445-449.

Cain, S.A. (1944) Foundations of plant geography. Harper \& Brothers, New York.

Carson, H.L. (1959) Genetic conditions which promote or retard the formation of species. Cold Spring Harbor Symposia on Quantitative Biology, 24, 87-105.

Cox, G.W. (1990) Centres of speciation and ecological differentiation in the Galapagos land bird fauna. Evolutionary Ecology, 4, 130142.

Cox, G.W. \& Ricklefs, R.E. (1977) Species diversity, ecological release, and community structuring in Caribbean land bird faunas. Oikos, 29, 60-66.

Darlington, P.J. Jr (1957) Zoogeography: the geographical distribution of animals. Wiley, New York.

Dynesius, M. \& Jannson, R. (2000) Evolutionary consequences of changes in species' geographical distributions driven by Milankovitch climate oscillations. Proceedings of the National Academy of Sciences USA, 97, 9115-9120.

Ebert, D. (1998) Experimental evolution of parasites. Science, 282, $1432-1435$.

Erwin, T.C. (1981) Taxon pulses, vicariance, and dispersal: an evolutionary synthesis illustrated by carabid beetles. Vicariance biogeography: a critique (ed. by G. Nelson and D.E. Rosen), pp. 159-196. Columbia University Press, New York.

Fleischer, R.C., McIntosh, C.E. \& Tarr, C.E. (1998) Evolution on a volcanic conveyor belt: using phylogeographic reconstructions and $\mathrm{K}$-Ar-based ages of the Hawaiian Islands to estimate molecular evolutionary rates. Molecular Ecology, 7, 533-545.

Frank, S. (1996) Models of parasite virulence. Quarterly Review of Biology, 71, 37-78.

Gaston, K.J. (1998) Species-range size distributions: products of speciation, extinction and transformation. Philosophical Transactions of the Royal Society of London - Series B: Biological Sciences, 353, 219-230.

Grant, P.R. (2001) Reconstructing the evolution of birds on islands: 100 years of research. Oikos, 92, 385-403.
Greenslade, P.J.M. (1968a) The distribution of some insects of the Solomon Islands. Proceedings of the Linnaean Society, London, 179, 189-196.

Greenslade, P.J.M. (1968b) Island patterns in the Solomon Islands bird fauna. Evolution, 22, 751-761.

Greenslade, P.J.M. (1969) Insect distribution patterns in the Solomon Islands. Philosophical Transactions of the Royal Society B, 255, 271-284.

Hunt, J.S., Bermingham, E. \& Ricklefs, R.E. (2001) Molecular systematics and biogeography of Antillean thrashers, tremblers, and mockingbirds (Aves: Mimidae). Auk, 118, 35-55.

James, H.F. \& Olson, S.L. (1991) Descriptions of thirty-two new species of birds from the Hawaiian Islands: Part II. Passeriformes. Ornithological Monographs, 46, 1-88.

Klein, N.K. \& Brown, W.M. (1994) Intraspecific molecular phylogeny in the yellow warbler (Dendroica petechia), and implications for avian biogeography in the West Indies. Evolution, 48, 19141932.

Klicka, J. \& Zink, R.M. (1997) The importance of recent ice ages in speciation: a failed paradigm. Science, 277, 1666-1669.

Lack, D. (1947) Darwin's finches. Cambridge University Press, Cambridge.

Lack, D. (1976) Island biology illustrated by the land birds of Jamaica. University of California Press, Berkeley, CA.

Lenski, R.E. \& May, R.M. (1994) The evolution of virulence in parasites and pathogens: reconciliation between two competing hypotheses. Journal of Theoretical Biology, 169, 253-265.

Liebherr, J.K. \& Hajek, A.E. (1990) A cladistic test of the taxon cycle and taxon pulse hypotheses. Cladistics, 6, 39-59.

Losos, J.B. (1990) A phylogenetic analysis of character displacement in Caribbean Anolis lizards. Evolution, 44, 558-569.

Lovette, I.J., Bermingham, E. \& Ricklefs, R.E. (1999a) Mitochondrial DNA phylogeography and the conservation of endangered Lesser Antillean Icterus orioles. Conservation Biology, 15, 1088-1096.

Lovette, I.J., Bermingham, E., Seutin, G. \& Ricklefs, R.E. (1998) Evolutionary differentiation in three endemic West Indian warblers. Auk, 115, 890-903.

Lovette, I.J., Bermingham, E., Seutin, G. \& Ricklefs, R.E. (1999b) The origins of an island fauna: a genetic assessment of sources and temporal patterns in the avian colonization of Barbados. Biological Invasions, 1, 33-41.

MacArthur, R.H. \& Wilson, E.O. (1967) The theory of island biogeography. Princeton University Press, Princeton, New Jersey.

Matsuda, H. \& Abrams, P.A. (1994) Runaway evolution to selfextinction under asymmetrical competition. Evolution, 48, 17641772.

Miles, D.B. \& Dunham, A.E. (1996) The paradox of the phylogenycharacter displacement analyses of body size in island Anolis. Evolution, 50, 594-603.

Pielou, E.C. (1979) Biogeography. Wiley, New York.

Pimentel, D. (1961) Animal population regulation by the genetic feedback mechanism. American Naturalist, 95, 65-79.

Pimentel, D. \& Al-Hafidh, R. (1963) The coexistence of insect parasites and hosts in laboratory populations. Annals of the Entomological Society of America, 56, 676-678.

Pimentel, D., Feinberg, E.H., Wood, P.W. \& Hayes, J.T. (1965) Selection, spatial distribution, and the coexistence of competing fly species. American Naturalist, 99, 97-109. 
Pregill, G.K. \& Olson, S.L. (1981) Zoogeography of West Indian vertebrates in relation to Pleistocene climatic cycles. Annual Review of Ecology and Systematics, 12, 75-98.

Pregill, G.K., Steadman, D.W. \& Watters, D.R. (1994) Late Quaternary vertebrate faunas of the Lesser Antilles: historical components of Caribbean biogeography. Bulletin of the Carnegie Museum of Natural History, 30, 1-51.

Raffaele, H., Wiley, J., Garrido, O., Keith, A. \& Raffaele, J. (1998) A guide to the birds of the West Indies. Princeton University Press, Princeton, New Jersey.

Ricklefs, R.E. (1970) Stage of taxon cycle and distribution of birds on Jamaica, Greater Antilles. Evolution, 24, 475-477.

Ricklefs, R.E. \& Bermingham, E. (1999) Taxon cycles in the Lesser Antillean avifauna. Ostrich, 70, 49-59.

Ricklefs, R.E. \& Bermingham, E. (2001) Nonequilibrium diversity dynamics of the Lesser Antillean avifauna. Science, 294, 1522-1525.

Ricklefs, R.E. \& Cox, G.C. (1972) Taxon cycles in the West Indian avifauna. American Naturalist, 106, 195-219.

Ricklefs, R.E. \& Cox, G.W. (1978) Stage of taxon cycle, habitat distribution, and population density in the avifauna of the West Indies. American Naturalist, 112, 875-895.

Ricklefs, R.E. \& Fallon, S.M. (2002) Diversification and host switching in avian malaria parasites. Proceedings of the Royal Society of London B, 269, 885-892.

Roughgarden, J. \& Pacala, S. (1989) Taxon cycles among. Anolis lizard populations: review of the evidence. Speciation and Its Consequences (ed. by D. Otte and J.A. Endler), Sinauer Associates, Sunderland, Massachusetts.

Roy, B.A. \& Kirchner, J.W. (2000) Evolutionary dynamics of pathogen resistance and tolerance. Evolution, 54, 51-63.

Sax, D.F. \& Brown, J.H. (2000) The paradox of invasion. Global Ecology and Biogeography, 9, 363-371.

Schneider, C.J., Losos, J.B. \& de Queiroz, K. (2001) Evolutionary relationships of the Anolis bimaculatus group from the northern Lesser Antilles. Journal of Herpetology, 35, 1-12.

Seutin, G., Brawn, J., Ricklefs, R.E. \& Bermingham, E. (1993) Genetic divergence among populations of a tropical passerine, the streaked saltator (Saltator albicollis). Auk, 110, 117-126.

Seutin, G., Klein, N.K., Ricklefs, R.E. \& Bermingham, E. (1994) Historical biogeography of the bananaquit (Coereba flaveola) in the Caribbean region: a mitochondrial DNA assessment. Evolution, 48, 1041-1061.

Simpson, G.G. (1949) The meaning of evolution. Yale University Press, New Haven, Connecticut.

Spitzer, K., Novotny, V., Tonner, M. \& Leps, J. (1993) Habitat preferences, distribution and seasonality of the butterflies (Lepidoptera, Papilionoidea) in a montane tropical rain forest, Vietnam. Journal of Biogeography, 20, 109-121.

Stattersfield, A.J., Crosby, M.J., Long, A.J. \& Wege, D.C. (1998) Endemic bird areas of the world. Priorities for biodiversity conservation. BirdLife International, Cambridge.

Steadman, D.W. (1989) Extinction of birds in eastern Polynesia: a review of the record, and comparisons with other Pacific island groups. Journal of Archaeological Science, 16, 177-205.
Steadman, D.W. (1995) Prehistoric extinctions of Pacific Island birds: biodiversity meets zooarcheology. Science, 267, 1123-1131.

Taper, M.L. \& Case, T.J. (1992) Models of character displacement and the theoretical robustness of taxon cycles. Evolution, 46, 317333.

Van Riper, C. III, Van Riper, S.G., Goff, M.L. \& Laird, M. (1986) The epizootiology and ecological significance of malaria in Hawaiian land birds. Ecological Monographs, 56, 327-344.

Wagner, W.L. \& Funk, V.A., eds (1995) Hawaiian biogeography: evolution on a hot spot archipelago. Smithsonian Institution Press, Washington, DC.

Whittaker, R.J. (1998) Island biogeography: ecology, evolution, and conservation. Oxford University Press, Oxford.

Williamson, M. (1981) Island populations. Oxford University Press, Oxford.

Willis, J.C. (1922) Age and area. A study in geographical distribution and origin in species. Cambridge University Press, Cambridge.

Wilson, E.O. (1959) Adaptive shift and dispersal in a tropical ant fauna. Evolution, 13, 122-144.

Wilson, E.O. (1961) The nature of the taxon cycle in the Melanesian ant fauna. American Naturalist, 95, 169-193.

\section{BIOSKETCHES}

Robert E. Ricklefs has had a long-standing interest in island biogeography since beginning his graduate studies with Robert H. MacArthur at the University of Pennsylvania in 1963. While a faculty member at Penn until 1995, he pursued his interests in West Indian birds with George W. Cox during the 1970s and beginning in 1989 with Eldredge Bermingham using molecular phylogenetic methods. After moving to the University of Missouri-St. Louis, where he is Curators' Professor of Biology, he has expanded the West Indian work to include the molecular phylogeography of avian malaria parasites. Related interests include the role of regional and historical factors in the generation and maintenance of global patterns of biodiversity.

Eldredge Bermingham received his graduate training in molecular phylogenetics and biogeography from John Avise at the University of Georgia. He has since worked on the historical biogeography of fish, with particular emphasis on the postIsthmian colonization of Central America by primary freshwater fish. In collaboration with coworkers at the Smithsonian Tropical Research Institute, he has applied molecular methods to such diverse problems as molecular clock calibration, coevolution, and the migration of human populations through Central America. He has a strong commitment to regional studies of biodiversity, to conservation in the Neotropics, and to the training of Latin American students. 